\title{
Piercing the Horizon
}

\section{Rodolphe Gasché}

Since Husserl - who, while attempting, in Ideas, to account for what really takes place in experience-introduced for the first time the concept of horizon as the foremost instrument of his analytic of intentionality (in order to conceptualize and analyze the specific mode of apprehension of the contextuality in which all experience of things takes place, that is, the pre-predicative assumption in natural life of the existence of the world, or the co-meant existence of the world in all judgments about particular things), any reference to this concept in phenomenological or post-phenomenological thought is also a reference to "world." Indeed, Husserl was the first to provide a thoughtfully developed concept of the world as a horizon which guides all understanding of whatever is encountered in the world. As a lawfully ordered interconnectedness of sense references, the "world," whether a particular world, or the One world which we all have in common, names the circumference, or frame, within which things can appear as things experienced, and which guides their intelligibility at all levels of understanding. However different, both the particular worlds and the One world are horizons. In natural experience, "the vital horizon [lebendiger Horizont]" of the active apperception of transcendent things is made up of the open infinity of all potential perceptions (based on all that which is given in non-thematic fashion, together with the thing in focus) as well as by a thing's proximity to the other things by which it always finds itself surrounded. ${ }^{1}$ By contrast, the universal horizon of the One world is the open space for the manifold particular worlds with their mobile and hence expandable and modifiable horizons, and which thus also transcends them as the universal dimension that makes all horizonal appearing and experience possible. 


\title{
RODOLPHE GASCHE
}

In his discussion of the life-world in Chapter III of The Crisis of the European Sciences and Transcendental Phenomenology Husserl makes a sharp distinction between the way particular things are apprehended within their own particular worlds, and the world horizon itself. Whereas in "normal, unbroken, coherent life ... world is the universal field into which all our acts, whether of experiencing, of knowing, or of outward action, are directed" without any explicit or thematic awareness of the horizonality of experience, the world as universal horizon is the result of a reflective attitude directed at the different ways in which the conscious having of the world occurs in natural life. ${ }^{2}$ Only in this new universal direction of interest does horizonality become thematic. As Elisabeth Ströker notes:

\begin{abstract}
'Horizonality' is not a title for a descriptively discovered complex within the natural attitude, but rather a title for what is phenomenologically exhibited in pure consciousness. As the basic structure of the objectively appearing world, it requires a search for the corresponding processes on the side of experience. For according to the universal a priori correlation between world and consciousness, the world must present itself in consciousness, and consciousness must maintain the structural conditions for the constitution of the world. ${ }^{3}$
\end{abstract}

The One world which transcends all other particular worlds - the koinon, or universal world - is something distinct from a partial horizon. But in no way does the One world horizon amount to a universalizing expansion of one such particular horizon, nor of the sum total of all particular horizons. The horizon of horizons, which can never be adequately apprehended in intuitive self-givenness, must be built, as a reading of The Crisis would demonstrate, from an analysis of the intersubjective meaning-giving acts of a transcendental Ego sedimented in the particular horizons of the life-world. The ultimate horizon of the One world is, indeed, an idea, more precisely, an idea in the Kantian sense.

The concept of horizon and, in particular, the world-horizon - understood either as the product of intersubjective meaning constitution (Husserl); or as that which guides all understanding of Being, namely, time (Heidegger); or as the extra-subjective objectivity that underpins all functions of the understanding of beings in the sphere of phenomenality (Patoèka) - plays a considerable role in 


\section{PIERCING THE HORIZON}

Derrida's thought as well. From early on he has repeatedly broached this theme which, in Sur Parole, he even termed "a grand philosophical question." Yet, considering the capital importance in phenomenological thought of this concept, it is somewhat surprising, at first, to remark that on almost all occasions at which Derrida raises the question of the horizon, he is strongly critical of it. ${ }^{5}$ Although Derrida's treatment of this concept would warrant an extensive discussion, we must confine ourselves to some very succinct remarks. First, however, a brief reminder of the Greek origin of the word may be appropriate. "Horizon" derives from the verb horizein, to divide or separate from, as a border or boundary. Horismos means limit, and horizon is a separating circle. Not only does the verb horizein thus refer to a marking out, or a tracing of borders by which a setting into limits occurs, according to Liddel and Scott, it also signifies "to ordain," "to determine", and " to lay down." Now, for Derrida, a horizon is "an inevitably totalizing horizon," and on occasion he even speaks of it as being "dark, threatening and threatened." ${ }^{\prime}$ One of Derrida's earliest discussions of Husserl's concept of horizon occurs in his 1962 commentary on Husserl's "Origin of Geometry," where Husserl defines the world (i.e., "the universe of Objects insofar as it is linguistically expressible in its being and its beingsuch") as the infinite horizon of every possible experience. Derrida writes:

Thus, the signification of the world as horizon is clearly explicated, i.e., as the infinitely open common place for everything we can encounter in front of and for ourselves. In front of and for ourselves implies, then, given as an object. The world, therefore, is essentially determined by the dative and horizontal dimension of being perceived (l'être-percu) in a gaze whose object must always be able to be a theorem. Geometrical exemplariness undoubtedly results from the fact that, as an 'abstract' material science, this exemplariness treats the spatiality of bodies (which is only one of the body's eidetic components), i.e., treats what confers sense on the notion of horizon and object. Despite all the antagonistic motifs which animate phenomenology, space's privilege therein is in certain respects remarkable. It testifies to that 'objectivist' tendency which Husserl simultaneously opposes so vigorously, and yet which is only a period, an essential, and therefore irreducible, movement of thought. ${ }^{7}$ 


\section{RODOLPHE GASCHE}

In Husserlian phenomenology, horizonality, or the world as a horizon, is thus a concept that is fundamentally linked to the bodily and spatial structures of the universe, the very same ones on which, as we have shown elsewhere, the theoretical gaze that found expression in the exact sciences bases its claim of universality. The horizon is the infinite spatial openness for the manifestation of everything that lets itself be encountered as a bodily object, and it draws its very meaning from this eidetic component of bodily things. But, as is also clear, the world of objects and, mutatis mutandis, the horizon (if indeed the latter pertains, first and foremost, to corporeal things in space) is not, for Husserl, the entire world. Husserl's transcendentalist approach to the life-world, his search for a more encompassing universality than the one offered by the sciences, therefore stands in an antagonistic relation to this very notion of horizonality. But in spite of the fact that Husserl, in The Crisis of the European Sciences and Transcendental Phenomenology, sought to open the horizon up to include the universal structure of the accomplishments of world-constitution by the intersubjective acts of the transcendental ego, the objectivist conception of the horizon, as Derrida would seem to suggest, continues to cast a shadow on Husserl's broader conception of horizonality. If in his later works Derrida then speaks of the necessity to exceed, pierce, perforate, puncture, or even burst open the horizon, something, indeed, that from a phenomenological perspective can only be, if not simply a provocation, then at least complete nonsense, it is first of all in order to break the hold of geometry on the horizon or, more accurately, on our way of thinking world and universality.

This outrageous demand to pierce the horizon rests first and foremost on Derrida's inquiry into the coming about, or, what he also calls, the "invention of the entirely other" - invention, since in distinction from the programmable other who arrives in the order of the same, one has to prepare for the entirely other - that is, a coming about "that allows the coming of a still unanticipatable alterity and for which no horizon of waiting as yet seems ready, in place, available." ${ }^{\prime 8}$ More generally, the demand in question devolves from Derrida's probing of the nature of an event, and from his examination of the necessary conditions of eventness. In "The University Without Condition," Derrida contends that "if there is any, if there is such a thing [as an event], the pure singular eventness of what arrives or of who arrives and arrives to me (which is what I call the arrivant), it would suppose an irruption that punctures the horizon, interrupting any performative 


\section{PIERCING THE HORIZON}

organization, any convention, or any context that can be dominated by a conventionality." Even though Derrida takes issue here with the rules and conventions that, according to speech act theory, make a performative event possible, one can extend his critique of conventions and conventionality to the whole sphere of doxical beliefs, customs, and habits. Without the interruption, not only of the horizonality of a theorizable world of objects, but also of the horizon of expectations, anticipations, and precomprehensions characteristic of the life-world, no event, strictly speaking, will ever be able to occur. To take this one step further: without piercing the horizon, whether in the sense of episteme, or in the sense of doxa; without bursting open the objectivist horizon of the exact sciences, or the subjectivist one of everyday beliefs, conventions, and expectations, no world worth its name - that is, no universal world - can come into being.

Let us keep the broader implications of Derrida's demand to burst open the horizon in mind as we now return to a discussion of some of his critical observations about the phenomenological concept of horizon. Especially when horizon is understood as "a horizon of anticipation or precomprehension," a formulation which recalls Husserl's talk, in Experience and Judgment, of the "structure of anticipation and fulfillment" characteristic of a horizon, a horizon is seen as "a horizon, period," and is subject to suspicion. ${ }^{10}$ In "Force of Law," for example, Derrida writes: "One of the reasons I'm keeping such a distance from all these horizons - from the Kantian regulative idea or from the messianic advent, for example, or at least from their conventional interpretation - is that they are, precisely horizons. As its Greek name suggests, a horizon is both the opening and the limit of that opening that defines an infinite progress or a period of waiting." 11 Derrida's criticism of the notion of horizon - which, as I have already remarked earlier, occurs in particular in his discussion of what constitutes an event - aims at dislocating the space in which something takes place, in which it is opened up, but, by the same stroke, is also encased within certain limits. In his commentary on Husserl's "Origin of Geometry," Derrida had already pointed out that the notion of horizon in Husserl's phenomenology concerns the concrete - because experienced conditions of possibility of history, that is, "a primordial knowledge" presupposed by "the totality of possible historical experiences." $\mathrm{He}$ notes: "Horizon is the always-already-there of a future which keeps the indetermination of its infinite openness even though this future was announced to consciousness. As the structural determination of every 


\section{RODOLPHE GASCHE}

material indeterminacy, a horizon is always virtually present in every experience; for it is at once the unity and the incompletion for that experience - the anticipated unity in every incompletion." ${ }^{12}$

Besides being intimately linked to world, horizonality is also determinative of history insofar as the latter concerns the expansion of the world to the One universal world that is shared by all. The paradox of the horizon however is that it both opens up the indeterminacy of the future while closing it in the same breath by anticipating what that future brings. Yet, while in this early Derridean text the horizon only seems to anticipate structurally and determine the future in advance, it does not seem to interfere with the material indeterminacy of the latter. By contrast, all references to the horizon in Derrida's later work would seem to suggest that, as a structure of anticipation and precomprehension, the horizon also encroaches on the material indeterminacy of future events, and this to such a degree that any history (and by the same token, any world worth its name) becomes impossible. Indeed, structured by anticipation and precomprehension, the horizon describes a space (and a time) in which whatever happens, or takes place, remains controllable and programmable - always already possible - in short, anticipatable and even calculable. What occurs within a horizon "is of the order of the masterable possible, it is the unfolding of what is already possible. It is of the order of power, of the 'I can," 'I may,' or 'I am empowered to...'. No surprise, thus no event in the strong sense." Where there is a horizon, "an event worthy of the name cannot arrive. If what arrives belongs to the horizon of the possible, or even of a possible performative, it does not arrive, it does not happen, in the full sense of the word." ${ }^{13}$ Now since, within the horizon, an event can only take place on the condition that the horizon master it as something possible in advance (thereby precluding any surprise), Derrida proclaims the need to exceed, pierce, perforate, puncture, or even burst open the horizon (all these being expressions that mark his discussion of horizonality).

Already in "Signature, Event, Context," where horizonality is discussed in terms of the communication of consciousnesses or presences within which the linguistic and semantic transport of meaning (vouloir-dire) occurs (as well as in terms of the semantic and hermeneutic horizon, that is, the horizon of sense which commands the notion of communication within which all meaning takes place), the nuclear traits characteristic of writing (in the sense of arche-writing) were said to exceed and puncture [excédé ou creve] these horizons. ${ }^{14}$ In a debate over 


\section{PIERCING THE HORIZON}

the hermeneutic conception of the horizon in Spurs, Derrida adds that "reading [as well], which is to relate to writing, is to perforate such an horizon or the hermeneutic veil." 15 As we have pointed out, in speaking of eventness Derrida observes that if there is such a thing as an "event in the strong sense ... it would suppose an irruption that punctures [crève] the horizon." ${ }^{16}$ Furthermore, in regards to "revolution," understood as an interruption of, and a radical caesura in, the ordinary course of history, that is, as an event which does not let itself be pre-programmed, Derrida notes that "in a certain way, as the only event worthy of the name, [a revolution] exceeds every possible horizon, every horizon of the possible - and therefore of potency and power." ${ }^{17}$ However, if the thought of the event - or for that matter of revolution, responsibility, decision, the coming of the other, and so forth - requires exceeding, puncturing, piercing, or perforating the horizon, this in no way implies abandoning or simply doing away with the horizon altogether. However provocative the talk in question may be, puncturing the horizon does not entail the all-out rejection of phenomenological horizonality.

Undoubtedly, Derrida has occasionally, linked the occurrence of an event to the absence altogether of a horizon. In Sur Parole, he remarks: "It is the absence of the horizon which is the condition of the event ... The absence of the horizon causes fear, but it is perhaps the condition for something unheard of to happen." ${ }^{18}$ However, as Derrida's reference, in For What Tomorrow ... A Dialogue, to the necessity of "maintain[ing a] horizon without horizon," if something such as unconditional hospitality is to be thought demonstrates, the notion of horizon is not to be relinquished once and for all. ${ }^{19} \mathrm{It}$ is certainly true, as Helmut Kuhn remarks, that "by its very nature every horizon is 'open.' As we move from the center toward the circumference fresh horizons open up. We are constantly invited to transcend the boundary of our field or vision." ${ }^{20}$ But it is also true that all these horizons are at the same time framed by what, in Husserl's words, is "the horizon of all horizons" - that is, the ultimate foundation of all actual and potential experience in an idea, which although merely regulative, and hence only the object of an infinite approximation or fulfillment, nonetheless suggests a pre-closed whole. In his call for the puncturing of the horizon, Derrida would then seem to extend to the horizon of all horizons, i.e., the universal horizon of the world, the constitutive transcendence of all particular horizons. However, if the horizon of all horizons is an idea in the Kantian sense, this horizon, rather as something always already given, is, as one could show on the basis of the last part of The 


\section{RODOLPHE GASCHE}

Crisis, also a horizon in the making, if it is not even an idea itself in the making. In light of Derrida's emphasis, in "Violence and Metaphysics," that, contrary to what Levinas contends, Husserl never held that the perception of a transcendent thing could be completed in full adequation (and hence, could be fully determined once and for all), and that the infinite horizons within which a thing is experienced can not be reduced to disposable present objects, the call for puncturing the horizon could in a certain way be tantamount to thinking faithfully Husserl's conception of horizon (as an idea in the Kantian sense) to its radical conclusion. Indeed, in the essay in question, Derrida points out that

the Idea in the Kantian sense designates the infinite overflowing of a horizon which, by reason of an absolute and essential necessity which itself is absolutely principled and irreducible, never can become an object itself, or be completed, equaled, by the intuition of an object .... In phenomenology there is never a constitution of horizons, but horizons of constitution. That the infinity of the Husserlian horizon has the form of an indefinite opening, and that it offers itself without any possible end to the negativity of constitution (of the work of objectivation) - does this not certainly keep it from all totalization, from the illusion of the immediate presence of a plenitudinous infinity in which the other suddenly becomes unfindable? ? $^{21}$

As an idea in the Kantian sense, the ultimate horizon which frames all other horizons can thus not be a constituted totality. Yet, even though nothing which takes place in it is ever fully determinable, this horizon, notwithstanding the impossibility of ever providing a definite sense for that which occurs within it, remains something with respect to which everything that occurs becomes intelligible. If alterity is to have a chance to manifest itself, then even a horizon that can only be approximated in an infinite process must be pierced.

While only a burst horizon could allow something singularthat is, something other, hence, incalculable - to occur, an unforeseeable event is one that is also "necessarily without horizon." 22 However, in the same way as a "horizon without horizon" implies the freeing of the horizon of its enclosing circumference within, and with respect to which, alone, things can and must appear without therefore relinquishing all relation to it, just so does an event without horizon merely refer to a given horizon's inability semantically to saturate in advance the sense 


\section{PIERCING THE HORIZON}

of such an event, and thus to strip it of its singularity. To be recognized as an unforeseeable and radically singular event (as something universal, to the extent that it does not yield to inexorably particular expectations and pre-comprehensions), the event - a singular universal, as it were must at the same time burst open the horizon, be without a horizon, and negotiate its lack of intelligibility with some sort of horizon in order to be experienced and recognized as a singular event. Phenomenologically speaking, the demand to do away with the horizon as such is an absurdity, but as the formula of a "horizon without horizon" (or of an event without horizon), indicates, any call to puncture the horizon seeks first and foremost not only the cutting open of particular horizons (even if they may not have those "firm walls," or more precisely, the "walls hard as steel (stablharte Wand)" which, according to Max Scheler, enclose the "milieu" of human beings, that is, their worlds, or in Husserlian terms, their homeworlds), but above all the cutting open of the ultimate meaning-giving horizon, the universal horizon of the world, in order for an experience of alterity to be possible, and to open the space for the unforeseeable to come. ${ }^{23}$ Only by bursting open the horizon qua "horizon of the wait," in relation to which one waits only for what one already expects in advance; only by "awaiting without a horizon of the wait," is a "just opening" toward "the event that cannot be awaited as such, or recognized in advance therefore, [possible], to the event as the foreigner itself, to her or him for whom one must leave an empty place, always, in memory of the hope." ${ }^{24}$

However, if an event is "what comes to pass only once, a single time, a first and last time, in an always singular, unique, exceptional, irreplaceable, unforeseeable, and incalculable fashion," in short, "what happens or who happens precisely there where ... one no longer sees it coming, no longer horizontally: without prospect or horizon," then for an event to happen not only is the end (la fin) of the horizon required, but also - implicated by the latter - the end of "teleology, the calculable program, foresight, and providence." 25 Indeed, wherever there is a horizon, whatever happens is seen to be coming from, or to happen in light of this horizon. A horizon as a horizon of pre-comprehension is always already also a horizon of anticipation and teleological determination. Whatever happens within it has therefore already been present in some way.

It has already arrived or happened and is thus neutralized in its irruption. Everywhere there is a horizon and where 


\section{RODOLPHE GASCHE}

we can see something coming from out of some teleology or ideal horizon, some horizon of an idea, that is, from out of the seeing (voir) or the knowing (savoir) of an eidos, everywhere that ideality is possible ... this horizontal ideality, the horizon of this ideality, will have neutralized in advance the event, along with everything that, in any historicity worthy of this name, requires the eventfulness of the event. ${ }^{26}$

Derrida's reservation regarding all horizons includes the one provided by the idea in a Kantian sense, that is, not only by an idea of adequate determinability to which everything converges as towards a limit on which, however, it never fully closes in, but also as that from which everything that occurs is already ideally prefigured, progressively accomplishing it, even if there is no ultimate fulfillment to this process. ${ }^{27}$ A horizon as a Kantian idea, as a regulative idea for every event, is consequently also something which neutralizes the event in its very unpredictability - and hence, the singularity - that alone makes it an event worthy of the name. A horizon which thus serves as a telos of both pre-comprehension and anticipation is by the same token that which also inhibits all historicity. Derrida writes:

Whenever a telos or teleology comes to orient, order, and make possible a historicity, it annuls that historicity by the same token and neutralizes the unforeseeable and incalculable irruption, the singular and exceptional alterity of what (ce qui) comes, or indeed of who (qui) comes, that without which, or the one without whom, nothing happens or arrives. It is not only the question of the telos that is posed here but that of the horizon and of any horizontal seeing-come in general. ${ }^{28}$

What follows from all of this is that if the horizon is the horizon of the world, and in particular of the world that is common to all, i.e., the universal world, this world is not the world since in it every event is instantly neutralized: It would be a world, in which nothing happens, and thus not a world at all. Strictly speaking, the world opened up by the horizon is enclosed within limits that prevent anything nonanticipated and non-precomprehended from happening within its overture. It is, therefore, not an openness to begin with, if openness implies exposure toward otherness, singularity, the incalculable, the to come. No world worthy of its name comes into being within a horizon. 


\section{PIERCING THE HORIZON}

A first condition for a world to open up would thus entail bursting open the horizon as anticipatory and teleological - and that always means archeo-teleological - determination. But although no world worthy its name can come into being within a horizon, a horizon is also required to prevent the horizonless world from becoming an unworld - a monstrous "world."

University of Buffalo

\section{Notes}

${ }^{1}$ Edmund Husserl, The Crisis of the European Sciences and Transcendental Phenomenology, trans. D. Carr, Evanston: Northwestern University Press, 1970, p. 149. For the distinction between inner and outer horizon by which the horizon of the perception of a thing is thus made, see Helmut Kuhn, "The Concept of Horizon," in Philosophical Essays in Memory of Edmund Husserl, ed. M. Farber, New York: Greenwood Press, 1968, p. 112.

2 Husserl, Crisis, p. 144.

${ }^{3}$ Elisabeth Ströker, Husserl's Transcendental Phenomenology, trans. L. Hardy, Stanford, CA: Stanford University Press, 1993, p. 90.

${ }^{4}$ Jacques Derrida, Sur Parole. Instantanés philosophiques, La Tour d'Aigues: Editions de l'aube, 2005, p. 49.

${ }^{5}$ For a succinct discussion of Patoèka's conception of the horizon, see Ernst Wolfgang Orth, "Jan Patoèka und die Philosophie," in Studien zur Philosophie von Jan Patoèka, Munich: Verlag Karl Alber, 1985, p. 14.

${ }^{6}$ Jacques Derrida, Spectres of Marx. The State of the Debt, the Work of Mourning \& the New International, trans. P. Kamuf, London: Routledge, 1994, pp. 28, 52 .

${ }^{7}$ Jacques Derrida, Edmund Husserl's Origin of Geometry. An Introduction, trans. J. P. Leavey, Stony Brook, NY: Nicolas Hays, 1978, pp. 82-83 (trans. mod.).

${ }^{8}$ Jacques Derrida, "Psyche. Inventions of the Other," trans. C. Porter, Reading de Man Reading, eds. L. Waters \& W. Godzich, Minneapolis: University of Minnesota Press, 1989, p. 55.

'Jacques Derrida, "The University Without Condition," in Jacques Derrida, Without Alibi, trans. P. Kamuf, Stanford, CA: Stanford University Press, 2002, p. 234.

${ }^{10}$ Edmund Husserl, Experience and Judgment. Investigations in a Genealogy of Logic, trans. J. S. Churchill and K. Ameriks, London: Routledge \& Kegan Paul, 1973, p. 89. Jacques Derrida, "The University Without Condition," in Jacques Derrida, Without Alibi, trans. P. Kamuf, Stanford, CA: Stanford University Press, 2002, p. 234. 


\section{RODOLPHE GASCHE}

${ }^{11}$ Jacques Derrida, "Force of Law: The Mystical Foundation of Authority," trans. M. Quaintance, Cardozo Law Review, vol. 11, n. 5-6, 1990, p. 967 (trans. mod.).

${ }^{12}$ Derrida, Edmund Husserl's Origin of Geometry, p. 117.

${ }^{13}$ Derrida, "The University Without Condition," p. 234.

${ }^{14}$ Jacques Derrida, Margins of Philosophy, trans. A. Bass, Chicago: University of Chicago Press, 1982, pp. 316, 329.

${ }^{15}$ Jacques Derrida, Spurs. Nietzsche's Styles, trans. B. Harlow, Chicago: University of Chicago Press, 1979, p. 127 (trans. mod.).

${ }^{16}$ Derrida, “The University Without Condition," p. 234.

${ }^{17}$ Jacques Derrida and Elisabeth Roudinesco, For What Tomorrow ... A Dialogue, trans. J. Fort, Stanford CA: Stanford University Press, 2004, p. 83.

${ }^{18}$ Derrida, Sur Parole, p. 50.

${ }^{19}$ Derrida and Roudinesco, For What Tomorrow..., p. 60.

${ }^{20}$ Helmut Kuhn, "The Concept of Horizon," in Philosophical Essays in Memory of Edmund Husserl, ed. M. Farber, New York: Greenwood Press, 1968, p. 108.

${ }^{21}$ Jacques Derrida, Writing and Difference, trans. A. Bass, Chicago: University of Chicago Press, 1978, pp.120-121.

22 Jacques Derrida, Rogues. Two Essays on Reason, trans. P.-A. Brault and M. Naas, Stanford, CA: Stanford University Press, 2005, p. xiv.

${ }^{23}$ Max Scheler, Formalism in Ethics and Non-Formal Ethics of Values, trans. M. S. Frings and R. L. Funk, Evanston, IL: Northwestern University Press, 1973, pp. 144-145.

${ }^{24}$ Derrida, Specters of Marx, p. 65.

${ }^{25}$ Derrida, Rogues, p. 135.

${ }^{26}$ Derrida, Rogues, p. 143.

${ }^{27}$ From his early work to his contribution to Giovanna Borradori's Philosophy in a Time of Terror. Dialogue with Jürgen Habermas and Jacques Derrida (Chicago: University of Chicago Press, 2003), Derrida has consistently expressed reservations regarding the idea in a Kantian sense, i.e., the regulative idea. However, it is certainly not insignificant that the succinct critique of the idea in a Kantian sense found in Derrida's interview with Borradori is preceded by the following observation: "my reservations are not straightforward objections. They are precisely reservations. For lack of anything better, if we can say this about a regulative idea, the regulative idea remains perhaps an ultimate reservation. Though such a last recourse risks becoming an alibi, it retains a certain dignity; I cannot swear that I will not one day give in to it" (pp. 133-134).

${ }^{28}$ Derrida, Rogues, p. 128. 